\title{
A PSICOLOGIA SOCIAL COMO ESPECIALIDADE: PARADOXOS DO MUNDO PSI
}

\author{
Heliana de Barros Conde Rodrigues \\ Universidade do Estado do Rio de Janeiro
}

RESUMO: O artigo problematiza o processo de criação de uma especialidade em Psicologia Social, campo até então considerado imune à constituição dos especialismos tão comuns em nossa área de atuação. Para tanto, recorre a conceitos da Análise Institucional - Efeito Weber, Efeito Lukács, campo de intervenção e campo de análise -, que funcionam como ferramentas na apreciação tanto da história recente da Psicologia Social no Brasil quanto da definição oficial da Psicologia Social como especialidade.

PALAVRAS-CHAVE: Psicologia Social; especialidade; Análise Institucional.

\section{SOCIAL PSYCHOLOGY AS A SPECIALTY. PARADOXES OF THE PSYCHOLOGIST'S WORLD}

ABSTRACT: The article problematizes the creation process of a specialty in Social Psychology. Unlike other fields of our professional area, Social Psychology was until recent seen as immune to the constitution of speciality. The study is based on the concepts of Institucional Analysis, such as Weber Effect, Lukács Effect, intervention field and analysis field. Such concepts are used as tools in order to appreciate the recent history of the Social Psychology in Brazil and the official definition of Social Psychology as a specialty.

KEY-WORDS: Social Psychology, specialty, Institutional Analysis.

As ciências são um pouco como as nações, não existem verdadeiramente senão a partir do dia em que seu passado não as escandaliza mais (...). Desconfiemos, pois, daquelas que fazem com demasiado cuidado a arrumação de sua história

(Michel Foucault).

Olho para minha surrada carteira verde do CRP, com sua capa adornada pelas armas da república, que poucos possuem e quase todos estranham "Coisa de advogado, parece um passaporte!", geralmente exclamam. Emitida em um longínquo 1978, a carteira tipo caderninho ${ }^{1}$ tem páginas e páginas destinadas a anotações ${ }^{2}$, jamais feitas, por sinal. Hoje, poderia (mas não vai !) conter algo como "Especialista em...”. Só se for em indisciplina, penso.

Durante o final de semana prolongado precedente a este encontro, não parei de refletir sobre o que me fora encomendado pela ABRAPSO-Rio: falar, nesta mesa redonda, acerca de algo que me soa como um paradoxo - a Psicologia social como especialidade. Para-doxo, isto é, o que incomodamente se posta "ao lado" do que é denominado, então, doxa ("opinião"), e eu julgava seguro alicerce: uma junção entre "psico" e "social" supostamente avessa, em sua combinatória feliz, a qualquer tipo de monopolização unívoca (até aqui meu quinhão, ali começa o seu...).

Se não afastamos de imediato este companheiro aparentemente indesejável, ele nos provoca e incita a pensar. Resolvo aceitar o desafio, inclusive em seu aspecto mais desagradável: embora atual coordenadora de um Curso de Especialização em Psicologia Jurídica, sou pouco afeita a Leis, Decretos e Resoluções; sonho com mundos de éticas convergentes (em lugar de tantos "Faça" ou "Não faça"), mas a encomenda me força a percorrer infinidades de páginas povoadas de artigos, incisos, parágrafos ${ }^{3}$. Obriga, inclusive, a ler aquele quase esquecido decreto de 1977, que permite, hoje, dar um "corpo sarado" à minha carteirinha "da terceira idade", ao prever o registro de Psicólogo Especialista. Fico matutando: por que diabos foram desenterrar, no ano $2000^{4}$, esse especialismo que até então permanecera tão obscuro?

E mais ainda: como se chegou, em $2003^{5}$, a incluir, ao lado de outras tão questionáveis, mas tão tranqüilamente acatadas "áreas de conhecimento específico para a atuação do Psicólogo"6 - Psicologia Escolar/Educacional, Psicologia Organizacional e do Trabalho, Psicologia do Trânsito, Psicologia Jurídica (mea culpa!?), Psicologia do Esporte, Psicologia Hospitalar, Psicologia Clínica, Psicopedagogia e Psicomotricidade -, a nossa querida Psicologia Social, exatamente aquele possível ponto de convergência de todas as nossas lutas contra o que existe sempre de 
Rodrigues, H.B.C. "A Psicologia Social como especialidade: paradoxos do mundo Psi"

especializado em nosso domínio de saber ? - aspecto sintetizado por Robert Castel (1978) mediante um truísmo lapidar: "a psicologia psicologiza" (p.98). Os psicólogos sociais se julgavam livres dessa mortífera especialização-primeira, a situar em cada um, mônada recoberta de carcaça individualizante, a Verdade, a Responsabilidade, a Culpa - morais de Estado civil e/ou penal...de cada um !

Curiosamente, menos de um ano após a moralização especializante de nossa presumida "psicologia sem culpa", uma prima distante - esta, confortavelmente instalada do lado de dentro da carcaça - veio fazer-lhe companhia. Em 2004, também a Neuropsicologia vira especialidade ${ }^{7}$ e se completa o clichê totalizante (ou seria totalitário?): nossas lentes psi podem, agora, convergir para todo e qualquer lugar do espectro bio-psico-social. E nós com isso?

Terá sido porventura o silêncio frente às pretensas obviedades iniciais - qual no poema, a primeira flor que deixamos roubar ${ }^{8}$ - o que abriu caminho à empreitada mais recente, onde a especialidade "Psicologia Social" se vê definida como a que "atua fundamentada na compreensão da dimensão subjetiva dos fenômenos sociais" ? Ora, essa é a postura hegemônica desde o século...XVII (?),.... XVIII (?),...... XIX, mais precisamente, constituindo a funesta condição de nossa existência como disciplina e profissão, além se ser cada vez mais apregoada no mundo contemporâneo, neo-liberal-globalizado-heterogerido. Michel Serres o diz bem, em um aggiornamento da frase de Castel: "Não depende mais de nós que tudo dependa de nós" (SERRES, 1999, p.225). Com isso, o social é crescentemente psicologizado: cuide-se!; cuidado!; afaste-se dos riscos!; seja belo, saudável, durável, equilibrado, flexível, pois, se não o fizer, poderá tornar-se um "inútil para o mundo" (CASTEL, 1995, p.20).

Penso que nós, psicólogos sociais (mas...ainda saberemos quem somos nós?), temos procurado inventar/conceber coisa outra: a dimensão social desse tal subjetivo ${ }^{10}$. Em termos mais precisos, aliás, temos tentado imanentizar o que fora separado. Algo sabemos da "dor e delícia" dessa utopia ativamente exercida, seja como estudiosos, profissionais ou militantes. Também temos buscado, por sinal, imanentizar essas funções ditas "especializadas".

Retorno ao que antes indagava: terá sido efetivamente nosso silêncio ${ }^{11}$ o que permitiu não só que a Psicologia Social fosse "decidida" na $\mathrm{APAF}^{12}$ como "especialidade", como que o tão combatido Ato Médico, por exemplo, penetrasse na definição da tal prima intra-carcaça, a Neuropsicologia? Cito a resolução 002/2004 do CFP: dentre as funções do especialista em Neuropsicologia, inclui-se "auxiliar na tomada de decisões de profissionais de outras áreas, fornecendo dados que contribuam para as escolhas de tratamento medicamentoso e cirúrgico". Cumpre reconhecer que logo se acrescenta: "exceto as psicocirurgias". É de bom tom, mas não deixa de ser muito estranho...

Percebo-me irada, e a raiva nem sempre é boa companhia para o pensamento. Se prossigo nesta linha, faço um comício e não um debate. Sendo assim proponho, a partir de agora, um volteio para longe do "olho do furacão" - para a ele retornar mais tarde -, com base em dois pontos.

I

A Análise Institucional, paradigma ao qual sou muito afeiçoada, prefere os efeitos às leis. Mediante tal privilégio, faz uma decidida opção antipositivista: ao contrário das leis científicas, em que o ver faculta o prever - preceito sintetizado pela fórmula "assim tem sido, assim será" -, os efeitos estão invariavelmente ligados à preservação, deliberada ou involuntária, de determinadas condições de efetuação. Efeitos são contingências repetidas ou reforçadas, e não legalidades universais às quais estejamos, sem escapatória, sujeitados.

Dentre os inúmeros efeitos batizados pelos analistas institucionais, vale destacar dois. René Lourau (1972) fala em um Efeito Weber, e assim o caracteriza: "Quanto mais uma sociedade é racionalizada, mais se torna opaca para aqueles que a compõem, a tal ponto que o dito 'selvagem' sabe mais acerca de suas tecnologias e instituições do que nós, ditos 'civilizados', sobre as nossas" (p.10). Trata-se aqui, portanto, da ativa institucionalização de um desconhecimento, quer quanto ao processo de produção de bens materiais quer quanto à produção das relações sociais, de maneira geral.

Porém...todos desconhecem? Não exatamente. Alguns (e somente alguns) devem conhecer (para dirigir ou para fazer com que alguém dirija). A esse respeito, Lourau (2004a) define novo modo de funcionamento, apelidando-o Efeito Lukács: "à medida que progride, a ciência tem tendência a esquecer as condições de seu aparecimento, de seu desenvolvimento, por trás dos imperativos do 'objeto' e do 'método"'; produz-se, com isso, mais e mais "não-saber pela codificação particular de alguma disciplina, pela alocação num sistema, pelo recorte de um 'campo' e rejeição de tudo o que existe antes e em torno desse campo"(p.89).

O Efeito Lukács sugere que o conhecimento dos processos sociais pelos quais a ciência se torna possível costuma escapar à própria ciência, não porque ela seja "naturalmente má", mas porque se torna cada vez mais opaca à medida que se "aperfeiçoam" seus instrumentos, à medida que embarca em uma 
continuada "especialização" (HESS \& SAVOYE, 1993, p.75).

Efeitos, no entanto, não são leis imutáveis. De repente, não mais que de repente, ao final dos anos 1970, muitos psicólogos brasileiros puderam, à custa de um trabalho de análise de implicações ${ }^{13}$ (procedimento que a especialização veementemente repudia), perceber-se como "guardiães da ordem" - para usar o precioso título da tese de Cecília Coimbra ${ }^{14}$. Disseram-se então "psicólogos sociais de um novo tipo": não mais especializados (embora pudessem "saber" muito), não mais eleitos da academia (apesar de nela poderem estar), não mais cientistas de laboratórios experimentais (estes, sim, geralmente abandonados em função de seu artificialismo acrítico). Entre as tantas coisas que fizeram, criaram a Associação Brasileira de Psicologia Social (ABRAPSO). E parece bastante apropriado, neste momento, citar um fragmento da carta da ABRAPSO, na pena de Neusa Guareschi (companheira desta mesa), em resposta à consulta encaminhada pelo CFP acerca da criação da especialidade em Psicologia Social, datada de 5 de junho de 2002 (antes, portanto, que a APAF aprovasse a matéria):

.....- considerando, principalmente, o objetivo expresso no estatuto da ABRAPSO: "A ABRAPSO tem por finalidades garantir e desenvolver as relações entre pessoas dedicadas ao estudo, ensino, investigação e aplicação da Psicologia em uma perspectiva social no Brasil, (...)";

(.....)

A proposta de uma Especialidade em Psicologia Social não é coerente com a finalidade e a composição desta Associação, e, ainda, vem de encontro aos auspícios da luta pela compreensão de que toda a Psicologia é social, pois "Esta afirmação não significa reduzir as áreas específicas da Psicologia à Psicologia social, mas sim cada uma assumir dentro de sua especialidade a natureza histórico-social do ser humano." (Lane, Silvia, T.M. A Psicologia social e uma nova concepção do homem para a Psicologia. In: Lane, Silia.T.M. e Codo, W.(org.) Psicologia social: o homem em movimento. São Paulo: Brasiliense,1984,p.19.

A posição desta direção é de não legitimar uma ação que venha depor ao contrário desta luta e, também, não contribuir para a formação de uma especialidade em Psicologia Social, correndo o risco de delimitar o compromisso éticosócio-político que se quer para a prática de qualquer profissional em Psicologia como um fazer técnico somente dos profissionais especialistas nesta área ${ }^{15}$.

Os efeitos Weber e Lukacs são contingências repetidas ou reforçadas, não leis universais. Por conseguinte, podem ser combatidos através de efeitos analisadores - "acontecimentos ou fenômenos reveladores e ao mesmo tempo catalisadores; produtos de uma situação que agem sobre ela" (LOURAU, 2004b, p.132) -, como a carta recém-citada. Foram ignorados, contudo, os analisadores. Por quê? - fica a pergunta.

II

Começo a imaginar a réplica de um interlocutor imaginário: "Você trabalha com perspectivas teórico-políticas muito específicas e não é à toa que tantos Departamentos Universitários se intitulam 'Departamento de Psicologia Social e Institucional'. Você também está lançando uma 'fala de especialista'...em instituições"!!!".

Em primeiro lugar, não vejo o conectivo $e$ (de Social $e$ Institucional) como indicativo de uma diferença entre especialidades. Pelo contrário, percebo-o como introdutor de um indispensável adendo, devido justamente ao reconhecimento, por parte dos psicólogos sociais, de não estarem isentos, porque sociais, da necessidade de analisar permanentemente sua genealogia, suas condições (institucionais) de existência, teorização e ação.

Neste sentido, trago à discussão, mais uma vez apoiada na Análise Institucional, a distinção entre campo de intervenção e campo de análise. Ao combater os efeitos de desconhecimento - Weber e Lukács -, nós, psicólogos sociais, chegamos a explicitar - e o quanto isso foi árduo, pois nos acusavam de fazer política, não psicologia ${ }^{16}$ - que nossos campos de intervenção reconhecidos, habituais (Escolar, do Trabalho, Jurídico, Clínico etc.), se haviam configurado quando, em face de alguma "sacudidela" históricosocial (chamemo-la desterritorialização, presença de movimentos insólitos, ruptura etc.), ofertáramos uma resposta técnica (reterritorialização, harmonização funcional, captura) que, a partir de então, se fixara como "ação a encomendar" - se algo não funciona a contento (mas...de quem?), chame o psicólogo para que tudo volte a andar ordeiramente nas escolas, nas fábricas, nos presídios, nas famílias,...nas cabeças e nas bocas, em suma.

Frente a tal panorama, a Análise Institucional faculta pensar que se quase invariavelmente nos encomendam algo a partir de nossa genealogia, digamos, de psicotiras, nada nos obriga - a não ser algu- 
Rodrigues, H.B.C. "A Psicologia Social como especialidade: paradoxos do mundo Psi"

ma adesão a mandatos institucionais não analisados (porém nunca impossíveis de analisar) - a "colar" nosso campo de análise ao campo de intervenção prédefinido por tal encomenda, historicamente forjada. É o que diz a carta da ABRAPSO. Ou mesmo, sendo bastante tolerante, era o que diziam, de certa forma, as nove primeiras especialidades reconhecidas, todas elas campos de intervenção e, conseqüentemente, ainda capazes de acolher, na qualidade de campos de análise, dimensões analíticas "descoladas" de especialismos-desconhecimento.

Tive o cuidado, entretanto, de ler as definições dessas primeiras especialidades, contidas no Anexo 1 da Resolução 014/2000. Constituem, a meu ver, curiosas mesclas de descrições naturalizadas "do mal que temos feito" - legitimando práticas há muito problematizadas pelos próprios psicólogos -, com "o bem que deveríamos fazer" - via formulações proselitistas, semelhantes a manuais para uma psicologia asséptica e politicamente correta, no pior dos sentidos desta última expressão ${ }^{17}$.

Não quero cansá-los com citações e, por esse motivo, limito-me a mencionar fragmentos relativos à Psicopedagogia. Exemplo de descrição naturalizada e acrítica: este especialista "contribui para a detecção de problemas de aprendizagem do aluno.... e sua intevenção possibilita a redução significativa dos índices de fracasso escolar". Complementando tal descrição, apenas aparentemente neutra - visto que se a detecção dos problemas de aprendizagem do aluno produz uma redução significativa do fracaso escolar, o culpado do fracasso escolar deve ser, por mais que se acumulem análises histórico-sociais em contrário ${ }^{18}$, $o$ aluno -, encontramos uma espécie de "manual de ajuda para o bem proceder", mediante uma lição simultaneamente sentimentalóide e grandiloqüente sobre $o$ ato de aprender: "Esse trabalho pode ser desenvolvido em diferentes níveis, propiciando aos educadores conhecimentos para: a reconstrução de seus próprios modelos de aprendizagem, de modo que, ao se perceberem também como 'aprendizes', revejam seus modelos de ensinantes; (...) a percepção de como se processou a evolução dos conhecimentos na história da humanidade", e assim por diante ${ }^{19} \ldots$.

Para finalizar este ponto, cumpre reafirmar que a Psicologia Social não consiste naquele campo de intervenção que deveria substituir todos os outros por ser o único puro, bom ou belo, mas o campo de análise a ser permanentemente reinventado, em todas as nossas práticas profissionais e acadêmicas, no intuito de impedir a "colagem" entre o que temos feito (campo de intervenção) e o como, historicamente, o temos feito. Será preciso lembrar como, hegemonicamente, o temos feito? Invalidando os pobres, dizendo desestruturadas ou insuficientemente boas as suas famílias, atribuindo carências a culturas não-hegemônicas, incapacitando pessoas para a vida civil, prognosticando periculosidades a partir de virtualidades biográficas de tipo racista etc. etc... $* * *$

Concluindo, volto ao "olho do furacão" e retomo o diálogo com meu interlocutor imaginário. Diria ele: "Você, que se disse tão afeita aos efeitos e tão pouco às leis (jurídicas e científicas), acha realmente que essas resoluções têm tanta importância, a ponto de nos fazer escutar críticas por mais de meia hora?". Respondo, ao mesmo tempo, não e sim - o que de modo algum implica qualquer álibi de neutralidade.

NÃO, se pensarmos que, ditos ou não sociais, aqueles psicólogos que "metem o social em tudo" prosseguirão, alegremente contra-especialistas e indisciplinados, a pensar-praticar uma "genealogia de nosso presente": tentarão assim aprender, junto às pessoas interessadas em uma série variada de problemas, os limites que as transformações e/ou cristalizações históricas nos têm imposto, a fim de engendrar, ao lado dessas mesmas pessoas, possibilidades de transgredi-los. Em termos mais nítidos, esses psicólogos continuarão a rejeitar a definição, esta sim "especializada", da Psicologia Social como aquela disciplina (tão disciplinada!!) que estuda o comportamento do indivíduo quando influenciado por outrem - afirmação que carrega, e eu nem diria somente nas entrelinhas, o pressuposto de uma Psicologia universal, abstrata e triste, a reafirmar "o não influenciado por outrem", idéia platônica da nossa caverna privatizada/ privatizante e, por princípio, sempre-já-especializada-e-competente.

Mas eu responderia também SIM, ressaltando a importância deste debate. Concordando com Baremblitt (1998), julgo que no mundo há mais respostas que perguntas e que uma das principais estratégias de controle sociopolítico consiste em reduzir, a um campo delimitado, as perguntas, ou melhor, o registro do visível e do enunciável (e, a partir de então, consumível). Neste sentido, em nada é inócuo o registro, como especialidade, de uma Psicologia Social: tal registro a desloca do plano da produção de uma multiplicidade de ações analítico-críticas para o de um produto a ser meramente registrado-consumido nos mercados profissionais e acadêmicos do mundo contemporâneo. Para tanto, fez-se necessário, inclusive, desconsiderar a história da Psicologia Social no Brasil, ao afirmar ser o novo especialista aquele que "promove a problematização e construção de proposições que qualificam o trabalho e a formação no campo da Psicologia Social" ${ }^{20}$. Arrogando-se o começo de tudo, a Psicologia Social tornada especia- 
lidade se faz, portanto, um novo produtor de esquecimento-desconhecimento.

NOTAS:

${ }^{1}$ Durante a exposição oral, a carteira foi mostrada aos presentes: a maioria, aparentemente, não a conhecia, pois há muito deixou de ser confeccionada e oferecida aos psicólogos.

${ }^{2}$ Em 1977, o Decreto 79.822, que regulamenta a criação dos Conselhos de Psicologia, também prevê a inscrição profissional nas qualidades de Psicólogo e Psicólogo Especialista.

${ }^{3}$ Toda a legislação referida no texto está disponível no site do Conselho Federal de Psicologia: http:// www.pol.org.br .

${ }^{4}$ Resolução 014/2000 do CFP, que institui o título profissional de Especialista em Psicologia e o respectivo registro nos Conselhos Regionais.

${ }^{5}$ Resolução 005/2003 do CFP, que reconhece a Psicologia Social como especialidade em psicologia para fins de concessão e registro do título de especialista.

${ }^{6}$ Termos extraídos da Resolução 014/2000 do CFP.

${ }^{7}$ Resolução 002/2004 do CFP.

${ }^{8}$ Eis os versos, bastante conhecidos, a que se faz referência: "Na primeira noite eles se aproximam/ e roubam uma flor/ do nosso jardim./ E não dizemos nada./Na segunda noite, já não se escondem:/ pisam as flores,/ matam nosso cão,/ e não dizemos nada./ Até que um dia,/ o mais frágil deles/ entra sozinho em nossa casa,/ rouba-nos a luz, e,/ conhecendo nosso medo, / arranca-nos a voz da garganta./ E já não podemos dizer nada". O poema se chama No caminho, com Maiakóvski e não é de Brecht, como geralmente se pensa, mas do brasileiro Eduardo Alves da Costa. ${ }^{9}$ Resolução 005/2003 do CFP.

${ }^{10}$ Alguém poderia retrucar que se trata simplesmente de uma questão de palavras, havendo pouca ou nenhuma diferença entre as duas formulações ("dimensão subjetiva dos fenômenos sociais", como diz a Resolução 005/2003, e "dimensão social do subjetivo", conforme propomos). Embora o problema crucial seja combater a separação entre os âmbitos social e subjetivo, cumpre lembrar que o termo fenômeno costuma ser usado para designar uma experiência, uma aparência (ou, de forma mais rigorosa, um aparecimento à consciência); dimensão, por seu lado, geralmente remete a algo estrutural, subjacente e determinante. Por conseguinte, independentemente das intenções, a definição contida na Resolução 005/2003 sugere uma preponderância do subjetivo (designado como dimensão) sobre o social (designado como fenômeno). Pelo menos um cuidado maior com a linguagem seria recomendável em campo tão polêmico.

${ }^{11}$ Nos foruns da Internet que consultei, não vi mais do que umas poucas cartinhas à moda do "sim" ou "não" às especialidades, qual nas enquetes do tipo "você decide".

12 Assembléia de Políticas Administrativas e Financeiras, do Sistema Conselhos.

${ }^{13}$ É importante enfatizar a diferenca entre implicação (dedicação, esforço, compromisso) e análise de implicação (trabalho coletivo de elucidação dos vínculos afetivos, históricos e profissionais com as instituições). A respeito, pode-se consultar Lourau, 2004c.

${ }^{14} \mathrm{O}$ título completo da tese referida é Guardiães $d a$ Ordem: algumas práticas psi no Brasil do "milagre".

${ }_{15}$ Trecho transcrito do site da ABRAPSO: http:// www.abrapso.org.br (acesso em 11/11/2004).

${ }^{16} \mathrm{~A}$ acusação pressupunha que os demais agentes $p s i$ estivessem a salvo das relações de poder, além de considerá-las uma espécie de pecado do qual não se envergonhariam os acusadores, estes sim "verdadeiros cientistas".

${ }^{17}$ As expressões "o mal que temos feito" e "o bem que deveríamos fazer" são, evidentemente, impressionistas e metafóricas, buscando sintetizar uma problemática. Não julgamos, pelo fato de usá-las, que "o bem" e "o mal" existam, tampouco que os psicólogos possam atingi-los. No máximo, fazemos algo de "bom" ou de "mau" - historicamente circunstanciados e só assim avaliáveis.

${ }^{18}$ Levando em conta tantas especialidades, essas análises histórico-sociais deveriam ficar exclusivamente reservadas....aos especialistas $\mathrm{em}$ psicologia social?

${ }^{19}$ A transformação da apresentação oral em artigo faculta transcrever alguns trechos relativos a outras especialidades. Assim, por exemplo, o especialista em Psicologia Organizacional e do Trabalho "atua em atividades relacionadas [entre outras] à saúde do trabalhador"; "participa do processo de desligamento de funcionários de organizações"; "atua na relação capital-trabalho no sentido de equacionar e dar encaminhamento a conflitos organizacionais". Já o especialista em Psicologia Jurídica "auxilia juizados na assistência psicológica de menores [?!?] e seus familiares"; "presta atendimento e orientação a detentos e seus familiares visando à preservação da saúde"; "realiza (...) avaliação de periculosidade e outros exames psicológicos no sistema penitenciário". O especialista em Psicologia do Esporte, por sua vez, tanto orienta "a efetivação do esporte não competitivo de caráter profilático e recreacional para conseguir o bem-estar e qualidade de vida dos indivíduos" quanto atua "na transformação de padrões de comportamento que interferem na prática de atividade física regular e/ou competitiva". Por mais que se trate de enumerações que procuram cobrir, qual nos documentos 
da Organização Internacional do Trabalho (OIT), toda a amplitude das atividades desempenhadas, e não de um código de ética, decerto há sérias questões éticopolíticas envolvidas nessas listagens aparentemente descritivas - questões particularmente perceptíveis quando se dá atenção à seqüência de ações mencionada em cada especialidade, invariavelmente plena de conflitivas e, mesmo, de contradições.

${ }^{20}$ Resolução 005/2003 do CFP.

\section{REFERÊNCIAS:}

BAREMBLITT, G. Nunca más. Em Golini, J. (org.) Derechos Humanos en el final del milenio. Buenos Aires: Ediciones Instituyente, 1998.

CASTEL, R. Les métamorphoses de la question social. Paris: Fayard, 1995.

CASTEL, R. O psicanalismo. Rio de Janeiro: Graal, 1978.

COIMBRA, C.M.B. Guardiães da Ordem: algumas práticas psi no Brasil do "milagre". Rio de Janeiro: Oficina do Autor, 1995.

HESS, R. \& SAVOYE, A. L'analyse institutionelle. Paris: PUF, 1993.

LOURAU, R. Les analyseurs de l'Église. Paris: Anthropos, 1972.

LOURAU, R. Estudos históricos sobre a contrapedagogia. Em Altoé, S. (org.) René Lourau: analista institucional em tempo integral. São Paulo: Hucitec, 2004a.

LOURAU, R. Uma apresentação da Análise Institucional. Em Altoé, S. (org.) René Lourau: analista institucional em tempo integral. São Paulo: Hucitec, 2004b.

LOURAU, R. Implicação e sobreimplicação. Em Altoé, S. (org.) René Lourau: analista institucional em tempo integral. São Paulo: Hucitec, 2004c.

SERRES, M. Luzes: cinco entrevistas com Bruno Latour. São Paulo: Unimarco Editora, 1999.

Heliana de Barros Conde Rodrigues é professora adjunta do Departamento de Psicologia Social e Institucional/Instituto de Psicologia da Universidade do Estado do Rio de
Janeiro (UERJ).O endereço eletrônico da autora é: helianaconde@uol.com.br

Heliana de Barros Conde Rodrigues A psicologia social como especialidade: paradoxos do mundo Psi

Recebido: 14/03/2005

$1^{\mathrm{a}}$ revisão: 8/05/2005

Aceite final: 2/06/2005 